\title{
Analysis of predictors of adherent perinephric fat and its impact on perioperative outcomes in laparoscopic partial nephrectomy: a retrospective case-control study
}

\author{
Lu Fang ${ }^{1 \dagger}$, Huan $\mathrm{Li}^{2 \dagger}$, Tao Zhang ${ }^{1}$, Rui Liu ${ }^{1}$, Taotao Zhang ${ }^{1}$, Liangkuan Bi ${ }^{1}$, Dongdong Xie ${ }^{1}$, Yi Wang ${ }^{1}$ and
} Dexin $\mathrm{Yu}^{1 *}$

\begin{abstract}
Background: Adherent perinephric fat (APF), characterized by inflammatory fat surrounding the kidney, can limit the isolation of renal tumors and increase the operative difficulty in laparoscopic partial nephrectomy (LPN). The aim of this study was to investigate the predictors of APF and its impact on perioperative outcomes during LPN.

Methods: A total of 215 consecutive patients undergoing LPN for renal cell carcinoma (RCC) from January 2017 to June 2019 at our institute were included. We divided these patients into two groups according to the presence of APF. Radiographic data were retrospectively collected from preoperative cross-sectional imaging. The perioperative clinical parameters were compared between the two groups. Univariate and multivariate analyses were performed to evaluate the predictive factors of APF.

Results: APF was identified in 41 patients (19.1\%) at the time of LPN. Univariate analysis demonstrated that APF was significantly correlated with the male gender $(P=0.001)$, higher body mass index $(P=0.002)$, lower preoperative estimated glomerular filtration rate $(P=0.004)$, greater posterior perinephric fat thickness $(P<0.001)$, greater perinephric stranding $(P<0.001)$, and higher Mayo Adhesive Probability (MAP) score $(P<0.001)$. The MAP score $(P<0.001)$ was the only variable that remained an independent predictor for APF in multivariate analysis. We found that patients with APF had longer operative times $(P<0.001)$, warm ischemia times $(P=0.001)$, and greater estimated blood loss $(P=$ $0.003)$ than those without APF. However, there were no significant differences in surgical approach, transfusion rate, length of postoperative stay, complication rate, or surgical margin between the two groups.
\end{abstract}

Conclusions: Several specific clinical and radiographic factors including the MAP score can predict APF. The presence of APF is associated with an increased operative time, warm ischemia time, and greater estimated blood loss but has no impact on other perioperative outcomes in LPN.

Keywords: Adherent perinephric fat, Laparoscopic partial nephrectomy, Renal cell carcinoma, Mayo Adhesive Probability score

\footnotetext{
*Correspondence: ay2fy_uro@126.com

†Lu Fang and Huan Li contributed equally to this work.

${ }^{1}$ Department of Urology, The Second Hospital of Anhui Medical University, 678 FuRong Road, Hefei 230601, Anhui Province, China

Full list of author information is available at the end of the article
}

\section{Background}

According to the European Association of Urology (EAU) Renal Cancer Guidelines, partial nephrectomy (PN) is the preferred option for clinical stage T1 renal tumors (defined as tumors of $\leq 7 \mathrm{~cm}$, confined to the original author(s) and the source, provide a link to the Creative Commons licence, and indicate if changes were made. The images or other third party material in this article are included in the article's Creative Commons licence, unless indicated otherwise in a credit line to the material. If material is not included in the article's Creative Commons licence and your intended use is not permitted by statutory regulation or exceeds the permitted use, you will need to obtain permission directly from the copyright holder. To view a copy of this licence, visit http://creativecommons.org/licenses/by/4.0/. The Creative Commons Public Domain Dedication waiver (http://creativeco mmons.org/publicdomain/zero/1.0/) applies to the data made available in this article, unless otherwise stated in a credit line to the data. 
renal parenchyma), when technically feasible [1]. With the increased availability and utilization of laparoscopic and robot-assisted techniques, minimally invasive PN (MIPN) has been identified as a safe and reproducible surgical approach, combining the advantages of decreased blood loss and hospital stay with similar oncological outcomes, compared with open PN [2-5]. In clinical practice, the treatment strategy of PN entails a complex decision process and is dependent on tumor and patient-specific factors [6, 7]. Several image-based tumor anatomical classification systems such as the PADUA classification system, the centrality index (C-index), and the RENAL nephrometry score system have been applied to evaluate the complexity and potential perioperative morbidity of PN [8-10]. Nevertheless, contemporary data assessing patient-specific factors that may also complicate the technical aspects of $\mathrm{PN}$ are limited.

Adherent perinephric fat (APF), a notable patientspecific factor, has attracted much attention over the years. APF, characterized by inflammatory fat surrounding the kidney, can restrict the isolation of renal tumors and increase the operative difficulty in PN [11-13]. Davidiuk et al. [14] proposed an image-based scoring algorithm called the Mayo Adhesive Probability (MAP) score to predict the presence of APF in robot-assisted PN (RAPN). However, the small cohort of patients enrolled and inadequate clinical predictors limit its extensive use. In this study, we sought to further investigate the predictive clinical and radiographic factors, including the MAP score, for APF, as well as to assess its impact on perioperative outcomes at the time of LPN.

\section{Methods}

\section{Patient selection and data collection}

With institutional review board approval, 300 consecutive patients who underwent LPN were prospectively analyzed in our institute from January 2017 to June 2019. The exclusion criteria were patients with an ipsilateral renal surgery history, who received preoperative neoadjuvant therapy, who had multifocal tumors, who had incomplete clinical information, and who had benign pathology. Eventually, 215 patients were enrolled in this study. Data were obtained regarding patients' baseline clinical characteristics (gender, age, body mass index (BMI), hypertension, diabetes mellitus, tobacco use, dyslipidemia, preoperative serum creatinine, estimated glomerular filtration rate (eGFR)) and pathological characteristics (pathological stage, histological subtype, Fuhrman grade, renal capsular invasion, and perinephric fat invasion).

Radiographic data (tumor size, tumor location, RENAL nephrometry score, posterior perinephric fat thickness, perinephric fat stranding, and MAP score) were collected from preoperative CT imaging within 1 month before LPN by two authors (LH and WY) who were independently blinded to the results of the operative notes. Posterior perinephric fat thickness was measured at the level of the renal vein as the distance from the renal capsule to the posterior abdominal wall, following a previously described procedure [15]. Perinephric fat stranding was defined in accordance with a prior study [16] as a line area of soft tissue attenuation in the perinephric space and was graded according to severity. The final MAP score was generated from the sum of the two parameters described above with a range from 0 to 5 [14].

LPN procedures were carried out similar to previously published methods [17] by one senior experienced urologist surgeon (YDX) and divided briefly into the following three steps: step 1, establishing the laparoscopic approach and operating space; step 2, dissecting the perinephric fat to expose the tumor and renal hilar vessels; and step 3 , resecting the tumor and closing the wound with hilar clamping.

A scoring algorithm was made to describe intraoperative perinephric fat adhesion, shown in Fig. 1 (0 points: no adhesions, blunt dissection with clear boundary, and rare bleeding; 1 point: mild adhesions, blunt dissection with clear boundary, and mild bleeding; 2 points: moderate adhesions, blunt and sharp dissection with still clear boundary, and moderate bleeding; 3 points: severe adhesions, sharp dissection with blurred boundary, and obvious bleeding, even requiring subcapsular dissection). APF was defined by the surgeon intraoperatively as a score for 3 points.

The perioperative variables collected from medical records were surgical approach, operative time, warm ischemia time (WIT), estimated blood loss (EBL), transfusion, length of postoperative stay, postoperative complication, surgical margin, and the incidence rate of renal capsule rupture. Postoperative complications within 30 days of surgery were graded according to the ClavienDindo classification [18].

Follow-up was carried out by postoperative outpatient interview and telephone interview until September 2021, disease recurrence, death, or loss to follow-up. Overall survival (OS) was identified as the interval between surgery and last follow-up or death with any cause. Recurrence-free survival (RFS) was identified as the interval between surgery and last follow-up or disease recurrence.

\section{Statistical analysis}

Normally and non-normally distributed continuous variables are summarized as means and standard deviations and medians (first quartile (Q1), third quartiles (Q3)), respectively. Categorical variables are reported as proportions with the number of patients. The distribution 

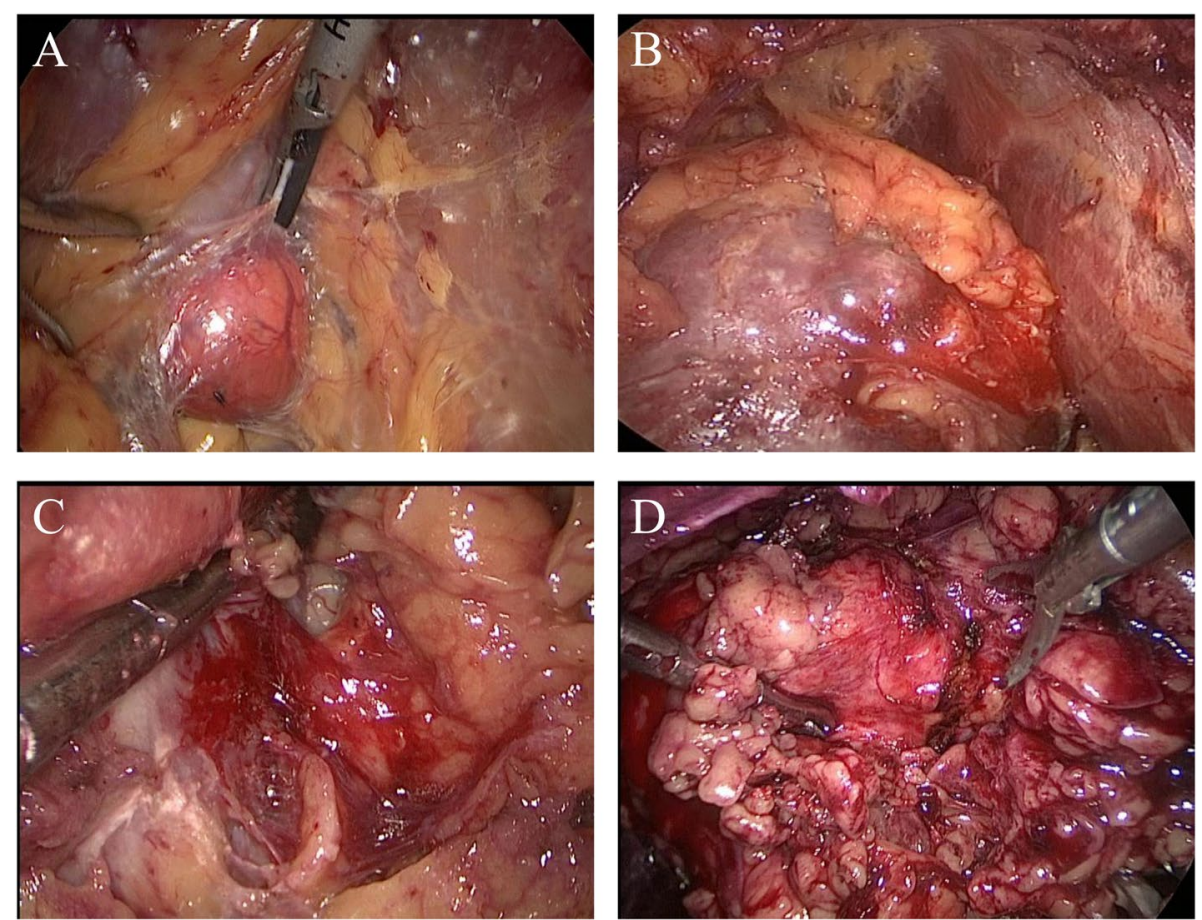

Fig. 1 Grading of intraoperative adhesions of perinephric fat. A 0 points: no adhesions, blunt dissection with clear boundary and rare bleeding; B 1 point: mild adhesions, blunt dissection with clear boundary and mild bleeding; $\mathbf{C} 2$ points: moderate adhesions, blunt and sharp dissection with still clear boundary, and moderate bleeding; D 3 points: severe adhesions, sharp dissection with blurred boundary, and obvious bleeding, even requiring subcapsular dissection

of continuous variables was checked by histograms and the Kolmogorov-Smirnov (K-S) test. Univariate and multivariate logistic regression analyses were performed to evaluate the predictive factors of APF. The differences in perioperative outcomes between patients with and without APF were compared using Student's $t$ test or the Mann-Whitney $U$ test for continuous variables. The chisquared test was used to compare categorical data. The survival curves were drawn according to the KaplanMeier method and compared using log-rank test. A $P$ value $<0.05$ indicates a statistically significant difference. All statistical analyses were performed using SPSS 20.0 statistical software (IBM, Chicago, IL, USA).

\section{Results}

\section{Characteristics of patients}

Of the 215 consecutive patients enrolled in the present study, 41 (19.1\%) had APF identified during LPN. Table 1 highlights the baseline characteristics of the cohort in detail. The mean age at the time of diagnosis was 57 years, and the majority of patients were male $(64.7 \%)$ and hypertensive $(54.0 \%)$ and had a mean BMI of 24.1 $\mathrm{kg} / \mathrm{m}^{2}$. The median preoperative serum creatinine was $70.0 \mu \mathrm{mol} / \mathrm{l}$, and the mean eGFR was $117.7 \mathrm{ml} / \mathrm{min} / 1.73$ $\mathrm{m}^{2}$. The mean tumor size was $3.7 \mathrm{~cm}$ with a standard deviation of $1.5 \mathrm{~cm}$. Pathological data revealed that most patients had a pT1 (91.1\%) stage tumor and a clear cell RCC subtype (78.1\%). The Fuhrman nuclear grade of RCC was marked on 174 patients, of whom 13 (7.5\%) had grade I, 132 (75.9\%) had grade II, and 29 (16.6\%) had grade III. Fifty $(23.3 \%)$ patients had renal capsular invasion, and $12(5.6 \%)$ patients had perinephric fat invasion. Perinephric fat stranding was graded as none, mild/ moderate, and severe in $51.2,33.5$, and $15.3 \%$ of patients, respectively. The mean posterior fat thickness was 1.1 $\mathrm{cm}$, median nephrometry score was $6(\mathrm{Q} 1, \mathrm{Q} 3: 6,8)$ and median MAP score was $2(\mathrm{Q} 1, \mathrm{Q} 3: 0,3)$. The proportion of patients with APF for each level of the MAP score was as follows: $0(n=68), 0 \% ; 1(n=38), 3 \% ; 2(n=24), 17 \%$; $3(n=52), 10 \% ; 4(n=25), 92 \%$; and $5(n=8), 100 \%$ (Fig. 2).

\section{Predictors of APF}

The clinical and radiographic variables predicting the presence of APF were evaluated by the logistic regression model. According to univariate analysis, APF significantly correlated with male gender (OR 4.963, $P=0.001$ ), higher body mass index (OR 1.171, $P=0.002$ ), lower preoperative estimated glomerular filtration rate (OR 0.983, $P=0.004)$, greater posterior perinephric fat thickness 
Table 1 Clinicopathological and radiographic characteristics stratified by the presence of adherent perinephric fat (APF)

\begin{tabular}{|c|c|c|c|}
\hline Variable & Total $(N=215)$ & APF group $(N=41)$ & Non APF group $(N=174)$ \\
\hline \multicolumn{4}{|l|}{ Gender $^{\mathrm{a}}$} \\
\hline Male & $139(64.7 \%)$ & $36(87.8 \%)$ & $103(59.2 \%)$ \\
\hline Age (years) ${ }^{b}$ & $57.1 \pm 13.4$ & $59.9 \pm 14.5$ & $56.5 \pm 13.1$ \\
\hline $\operatorname{BMI}\left(\mathrm{kg} / \mathrm{m}^{2}\right)^{\mathrm{b}}$ & $24.1 \pm 3.7$ & $25.7 \pm 3.7$ & $23.7 \pm 3.6$ \\
\hline Hypertension $^{\mathrm{a}}$ & $116(54.0 \%)$ & $27(65.9 \%)$ & $89(51.1 \%)$ \\
\hline Diabetes mellitus $^{\mathrm{a}}$ & $52(24.2 \%)$ & $13(31.7 \%)$ & $39(22.4 \%)$ \\
\hline Tobacco use & $70(32.6 \%)$ & $17(41.5 \%)$ & $53(30.5 \%)$ \\
\hline Dyslipidemia $^{a}$ & $88(41.0 \%)$ & $16(39.0 \%)$ & $72(41.4 \%)$ \\
\hline Preoperative creatinine $(\mu \mathrm{mol} / \mathrm{l})^{c}$ & $70.0(58.0,84.0)$ & $80.0(70.0,97.5)$ & $68.0(54.0,81.3)$ \\
\hline Preoperative eGFR $\left(\mathrm{ml} / \mathrm{min} / 1.73 \mathrm{~m}^{2}\right)^{\mathrm{b}}$ & $117.7 \pm 34.5$ & $103.6 \pm 30.1$ & $121.1 \pm 34.7$ \\
\hline Tumor size $(\mathrm{cm})^{b}$ & $3.7 \pm 1.5$ & $4.0 \pm 1.4$ & $3.6 \pm 1.5$ \\
\hline \multicolumn{4}{|l|}{ Tumor location ${ }^{\mathrm{a}}$} \\
\hline Left side & $105(48.8 \%)$ & $22(53.7 \%)$ & $83(47.7 \%)$ \\
\hline \multicolumn{4}{|l|}{ Pathological stage $\mathrm{a}^{\mathrm{a}}$} \\
\hline pT1a & $131(60.9 \%)$ & $22(53.7 \%)$ & $109(62.6 \%)$ \\
\hline pT1b & $65(30.2 \%)$ & $16(39.0 \%)$ & $49(28.2 \%)$ \\
\hline pT2a & $6(2.8 \%)$ & $1(2.4 \%)$ & $5(2.9 \%)$ \\
\hline$\geq \mathrm{pT3}$ & $13(6.1 \%)$ & $2(4.9 \%)$ & $11(6.3 \%)$ \\
\hline \multicolumn{4}{|l|}{ Histological subtype ${ }^{a}$} \\
\hline Clear cell & $168(78.1 \%)$ & $36(87.8 \%)$ & $132(75.9 \%)$ \\
\hline Papillary cell & $6(2.8 \%)$ & $1(2.4 \%)$ & $5(2.9 \%)$ \\
\hline Chromophobe & $12(5.6 \%)$ & $1(2.4 \%)$ & $11(6.3 \%)$ \\
\hline Other subtype & $29(13.5 \%)$ & $3(7.4 \%)$ & $26(14.9 \%)$ \\
\hline \multicolumn{4}{|l|}{${ }^{\mathrm{d}}$ Fuhrman grade ${ }^{\mathrm{a}}$} \\
\hline । & $13(7.5 \%)$ & $1(2.7 \%)$ & $12(8.8 \%)$ \\
\hline$\|$ & $132(75.9 \%)$ & $27(73.0 \%)$ & $105(76.6 \%)$ \\
\hline III & $29(16.6 \%)$ & $9(24.3 \%)$ & $20(14.6 \%)$ \\
\hline IV & $0(0.0 \%)$ & $0(0.0 \%)$ & $0(0.0 \%)$ \\
\hline Renal capsular invasion ${ }^{a}$ & $50(23.3 \%)$ & $11(26.8 \%)$ & $39(22.4 \%)$ \\
\hline Perinephric fat invasion ${ }^{a}$ & $12(5.6 \%)$ & $2(4.9 \%)$ & $10(5.7 \%)$ \\
\hline RENAL nephrometry score ${ }^{c}$ & $6.0(6.0,8.0)$ & $7.0(6.0,8.0)$ & $6.0(5.0,8.0)$ \\
\hline Posterior fat thickness $(\mathrm{cm})^{b}$ & $1.1 \pm 0.6$ & $2.0 \pm 0.6$ & $0.9 \pm 0.5$ \\
\hline \multicolumn{4}{|l|}{ Perinephric stranding ${ }^{\mathrm{a}}$} \\
\hline None & $110(51.2 \%)$ & $4(9.8 \%)$ & $106(60.9 \%)$ \\
\hline Mild/moderate & $72(33.5 \%)$ & $13(31.7 \%)$ & $59(33.9 \%)$ \\
\hline Severe & $33(15.3 \%)$ & $24(58.5 \%)$ & $9(5.2 \%)$ \\
\hline MAP score ${ }^{c}$ & $2.0(0.0,3.0)$ & $4.0(4.0,4.0)$ & $1.0(0.0,3.0)$ \\
\hline
\end{tabular}

$N$, number; $S D$, standard deviation; $Q$, quartile; $B M I$, body mass index; eGFR, estimated glomerular filtration rate; MAP, Mayo Adhesive Probability

${ }^{a} N(\%)$

${ }^{\mathrm{b}}$ Mean \pm SD

'Median (Q1, Q3)

${ }^{\mathrm{d}}$ Fuhrman grade, 174/215 had recorded Fuhrman grade

(OR 38.141, $P<0.001$ ), greater perinephric stranding (OR 5.839; OR 70.667, $P<0.001$ ), and higher MAP score (OR 8.945, $P<0.001$ ) (Table 2). Based on these factors, multivariate analysis demonstrated that the MAP score (OR 8.870, $P<0.001$ ) was the only variable that remained an independent predictor of APF (Table 3).
Impact of APF on perioperative outcomes in LPN

As shown in Table 4, most of the patients received a retroperitoneal approach (82.8\%) for LPN. Compared with the non-APF group, the APF group was associated with a significantly longer operative time (158.0 vs. $124.2 \mathrm{~min}$, $P<0.001)$, warm ischemia time (17.9 vs. $13.5 \mathrm{~min}, P=$ 


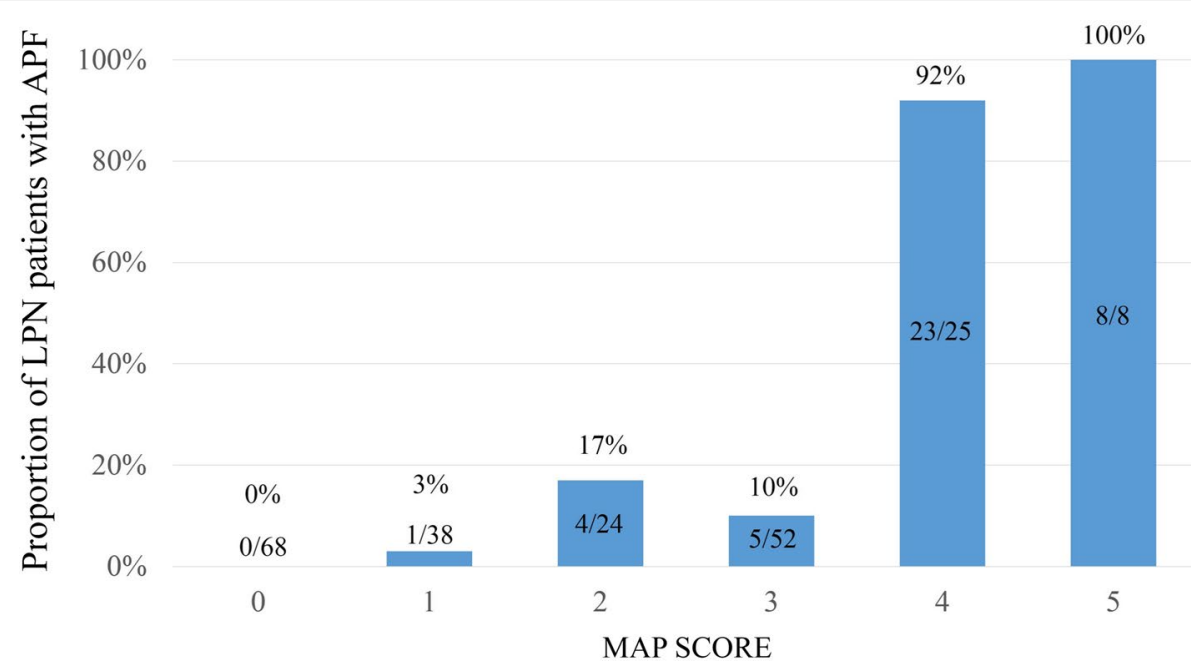

Fig. 2 Proportion of laparoscopic partial nephrectomy (LPN) patients with adherent perinephric fat (APF) according to the MAP score

0.001), greater estimated blood loss (80 vs. $50 \mathrm{ml}, P=$ $0.003)$, and higher incidence rate of renal capsule rupture (12.2\% vs. $1.7 \%, P=0.006)$. The rate of transfusion in this study population was relatively low (3.3\%), and there was no difference in the length of postoperative stay. Overall, 30-day complications and positive surgical margins occurred in 31.6 and $2.3 \%$ of patients, respectively, with no difference between the two groups.

\section{Association between APF and oncological outcomes of RCC patients}

The association between intraoperative APF and the prognosis of RCC patients were analyzed by the KaplanMeier method. The mean and median follow-up times were 38.5 and 37.0 months. Figure 3 shows the survival curves for OS and RFS and suggested that there was no significant difference between the APF group and non-APF group in OS $(P=0.828)$ and RFS $(P=0.783)$, respectively.

\section{Discussion}

Since LPN was first reported by Winfield et al. in 1993 [19], it has increasingly become a preferred approach for the surgical management of cT1 renal masses, given evidence supporting similar oncologic efficacy and better perioperative outcomes compared with open PN [2-5]. However, LPN is technically challenging because it requires not only a negative surgical margin resection but time-dependent renal reconstruction [20-23]. The implementation of LPN is affected by a variety of factors, including tumor size, location, depth, and its relationship to renal hilar vessels and the urinary collecting system. Several scoring systems that quantify renal tumor anatomical factors have been developed to evaluate the surgical complexity and perioperative outcomes. Among them, the PADUA classification system, C-index, and RENAL nephrometry score system are the most widely used algorithms [8-10]. Nevertheless, these algorithms focus entirely on tumor-specific factors and ignore patient-specific factors that may also play an essential role in the LPN procedure.

It is not an uncommon occurrence when performing PN that thick and adherent perinephric adipose tissues within the Gerota's fascia complicate the exposure of the renal parenchyma and tumor. As a notable patientspecific factor, APF has attracted much attention in the last decade. However, the definition of APF is still lack of a uniform standard. A series of definitions have been reported in the literature, such as inflammatory perirenal fat adhering to the renal parenchyma that makes kidney dissection difficult and results in bleeding and decapsulation [13] and perirenal fat within the Gerota's fascia requiring subcapsular dissection [14]. Differing from these relatively subjective definitions of APF, we made a scoring index based on the macroscopic appearance to describe intraoperative adhesions of perinephric fat, which may help to universalize its definition.

Prior studies have demonstrated that the presence of APF can result in adverse perioperative outcomes during MIPN. Kocher et al. revealed a statistically significant association among APF, longer operative time, and higher estimated blood loss [12]. Additionally, Khene et al. emphasized an elevated risk of conversion to open surgery or radical nephrectomy in patients with APF [13]. Similarly, in a large cohort of patients with RCC that underwent LPN, our data also identified APF as 
Table 2 Univariate logistic regression analysis for association of index variables and adherent perinephric fat (APF)

\begin{tabular}{|c|c|c|}
\hline \multirow[t]{2}{*}{ Variable } & \multicolumn{2}{|l|}{ Univariate analysis } \\
\hline & OR $(95 \% \mathrm{Cl})$ & $P$ value \\
\hline Gender & & 0.001 \\
\hline Male & $4.963(1.857-13.264)$ & \\
\hline Female & Reference & \\
\hline Age (years) & $1.020(0.993-1.047)$ & 0.145 \\
\hline $\mathrm{BMI}\left(\mathrm{kg} / \mathrm{m}^{2}\right)$ & $1.171(1.058-1.296)$ & 0.002 \\
\hline Hypertension & & 0.092 \\
\hline Yes & $1.842(0.905-3.749)$ & \\
\hline No & Reference & \\
\hline Diabetes mellitus & & 0.214 \\
\hline Yes & $1.607(0.761-3.396)$ & \\
\hline No & Reference & \\
\hline Tobacco use & & 0.178 \\
\hline Yes & $1.617(0.803-3.257)$ & \\
\hline No & Reference & \\
\hline Dyslipidemia & & 0.783 \\
\hline Yes & $0.907(0.452-1.819)$ & \\
\hline No & Reference & \\
\hline Preoperative creatinine $(\mu \mathrm{mol} / \mathrm{l})$ & $1.010(0.998-1.023)$ & 0.101 \\
\hline Preoperative eGFR (ml/min/1.73 $\left.\mathrm{m}^{2}\right)$ & $0.983(0.972-0.995)$ & 0.004 \\
\hline Tumor size $(\mathrm{cm})$ & $1.214(0.970-1.521)$ & 0.090 \\
\hline Tumor location & & 0.493 \\
\hline Left side & $1.269(0.642-2.511)$ & \\
\hline Right side & Reference & \\
\hline Pathological stage & & 0.290 \\
\hline pT1a & Reference & \\
\hline > pT1a & $1.448(0.729-2.877)$ & \\
\hline Histological subtype & & 0.103 \\
\hline cCRCC & Reference & \\
\hline Non-ccRCC & $0.437(0.161-1.184)$ & \\
\hline Fuhrman grade & & 0.234 \\
\hline । & Reference & \\
\hline$\|$ & $3.086(0.384-24.783)$ & \\
\hline III & $5.400(0.607-48.078)$ & \\
\hline Renal capsular invasion & & 0.548 \\
\hline Yes & $1.269(0.583-2.761)$ & \\
\hline No & Reference & \\
\hline Perinephric fat invasion & & 0.828 \\
\hline Yes & $0.841(0.177-3.994)$ & \\
\hline No & Reference & \\
\hline RENAL nephrometry score & $1.065(0.885-1.282)$ & 0.506 \\
\hline Posterior fat thickness (cm) & $38.141(12.524-116.156)$ & $<0.001$ \\
\hline Perinephric stranding & & $<0.001$ \\
\hline None & Reference & \\
\hline Mild/moderate & $5.839(1.821-18.719)$ & \\
\hline Severe & $70.667(20.078-248.724)$ & \\
\hline MAP score & 8.945 (4.160-19.236) & $<0.001$ \\
\hline
\end{tabular}

$O R$ odds ratio, $\mathrm{Cl}$ confidence interval, $\mathrm{BMI}$ body mass index, eGFR estimated glomerular filtration rate, $c C R C C$ clear cell renal cell carcinoma, MAP Mayo
Table 2 (continued)

Adhesive Probability

Table 3 Multivariate logistic regression analysis of adherent perinephric fat (APF)

\begin{tabular}{lll}
\hline Variable & \multicolumn{2}{l}{ Multivariate analysis } \\
\cline { 2 - 3 } & OR $\mathbf{( 9 5 \% ~ C l )}$ & P value \\
\hline Gender (male vs female) & $2.238(0.611-8.200)$ & 0.224 \\
BMI $\left(\mathrm{kg} / \mathrm{m}^{2}\right)$ & $0.957(0.826-1.108)$ & 0.555 \\
Preoperative eGFR $\left(\mathrm{ml} / \mathrm{min} / 1.73 \mathrm{~m}^{2}\right)$ & $1.000(0.983-1.016)$ & 0.969 \\
MAP score & $8.870(3.875-20.306)$ & $<\mathbf{0 . 0 0 1}$ \\
\hline
\end{tabular}

$O R$ odds ratio, $C l$ confidence interval, $B M I$ body mass index, eGFR estimated glomerular filtration rate, MAP Mayo Adhesive Probability

significantly correlated with an increased estimated blood loss $(P=0.003)$ and operative time $(P<0.001)$. We observed that APF had no impact on the surgical margins and postoperative complications. Additionally, under comparable surgeons' experience and tumor complexity, the warm ischemia time in cases with APF was 4 min longer than in those without APF $(P=0.001)$, which agreed with the finding from Borregales et al. [24]. The possible explanation for these results is as follows; adherent perinephric adipose tissues are more brittle and prone to bleeding, and when exposing and resecting the renal tumor, a blurred boundary caused by APF usually requires sharp dissection and an expanded scope of resection to ensure a negative surgical margin (Fig. 1), which further increases bleeding and suture difficulty and prolongs the warm ischemia time and operative time.

In view of the adverse perioperative outcomes associated with APF, a series of studies have been performed to investigate its physiologic mechanism and predictive factors. While the underlying pathogenesis of APF remains unclear, studies suggest that inflammation, idiopathic fibrosis, and the autoimmune response may account for APF [25]. Previous basic research has indicated the contributions of inflammation and fibrosis to abnormal adipose tissue expansion in obesity. Inflammation can lead to hypoxia and fibrosis in adipocytes, which can, in turn, promote the migration of immune cells into adipose depots [26]. As an index of obesity, the role of BMI in predicting APF is contentious. According to our univariate analysis, BMI was found to be closely associated with APF $(P=0.002)$, and similar findings were confirmed in other studies $[13,14]$. However, it has also been argued that there is no significant correlation between BMI and APF [12], probably because BMI does not accurately reflect the variation in fat distribution, especially visceral fat (obesity), which is strongly related to metabolic 
Table 4 Impact of adherent perinephric fat (APF) on perioperative outcomes in laparoscopic partial nephrectomy (LPN)

\begin{tabular}{|c|c|c|c|c|}
\hline Variable & Total $(N=215)$ & APF group $(N=41)$ & Non APF group $(N=174)$ & $P$ value \\
\hline Surgical approach ${ }^{\mathrm{a}}$ & & & & 0.344 \\
\hline Retroperitoneal & $178(82.8 \%)$ & $36(87.8 \%)$ & $142(81.6 \%)$ & \\
\hline Transperitoneal & $37(17.2 \%)$ & $5(12.2 \%)$ & $32(18.4 \%)$ & \\
\hline Operative time $(\min )^{b}$ & $130.7 \pm 41.0$ & $158.0 \pm 38.3$ & $124.2 \pm 39.0$ & $<0.001$ \\
\hline Warm ischemia time $(\mathrm{min})^{b}$ & $14.3 \pm 7.3$ & $17.9 \pm 7.2$ & $13.5 \pm 7.2$ & 0.001 \\
\hline Estimated blood loss $(\mathrm{ml})^{c}$ & $50.0(30.0,100.0)$ & $80.0(50.0,150.0)$ & $50.0(30.0,80.0)$ & 0.003 \\
\hline Transfusion ${ }^{\mathrm{a}}$ & $7(3.3 \%)$ & $3(7.3 \%)$ & $4(2.3 \%)$ & 0.254 \\
\hline Length of postoperative stay (days) ${ }^{c}$ & $8.0(7.0,9.0)$ & $8.0(7.0,9.0)$ & $8.0(7.0,9.0)$ & 0.191 \\
\hline Postoperative complication ${ }^{\mathrm{a}}$ & $68(31.6 \%)$ & $12(29.2 \%)$ & $56(32.2 \%)$ & 0.746 \\
\hline Clavien-Dindo I-II & $64(29.8 \%)$ & $11(26.8 \%)$ & $53(30.5 \%)$ & \\
\hline Clavien-Dindo III-IV & $4(1.8 \%)$ & $1(2.4 \%)$ & $3(1.7 \%)$ & \\
\hline Surgical margin ${ }^{\mathrm{a}}$ & & & & 0.957 \\
\hline Positive & $5(2.3 \%)$ & $1(2.4 \%)$ & $4(2.3 \%)$ & \\
\hline Negative & $210(97.7 \%)$ & $40(97.6 \%)$ & $170(97.7 \%)$ & \\
\hline Renal capsule rupture ${ }^{a}$ & $8(3.7 \%)$ & $5(12.2 \%)$ & $3(1.7 \%)$ & 0.006 \\
\hline
\end{tabular}

${ }^{\mathrm{a}} N(\%)$

${ }^{\mathrm{b}}$ Mean \pm SD

${ }^{\mathrm{C}}$ Median (Q1, Q3)
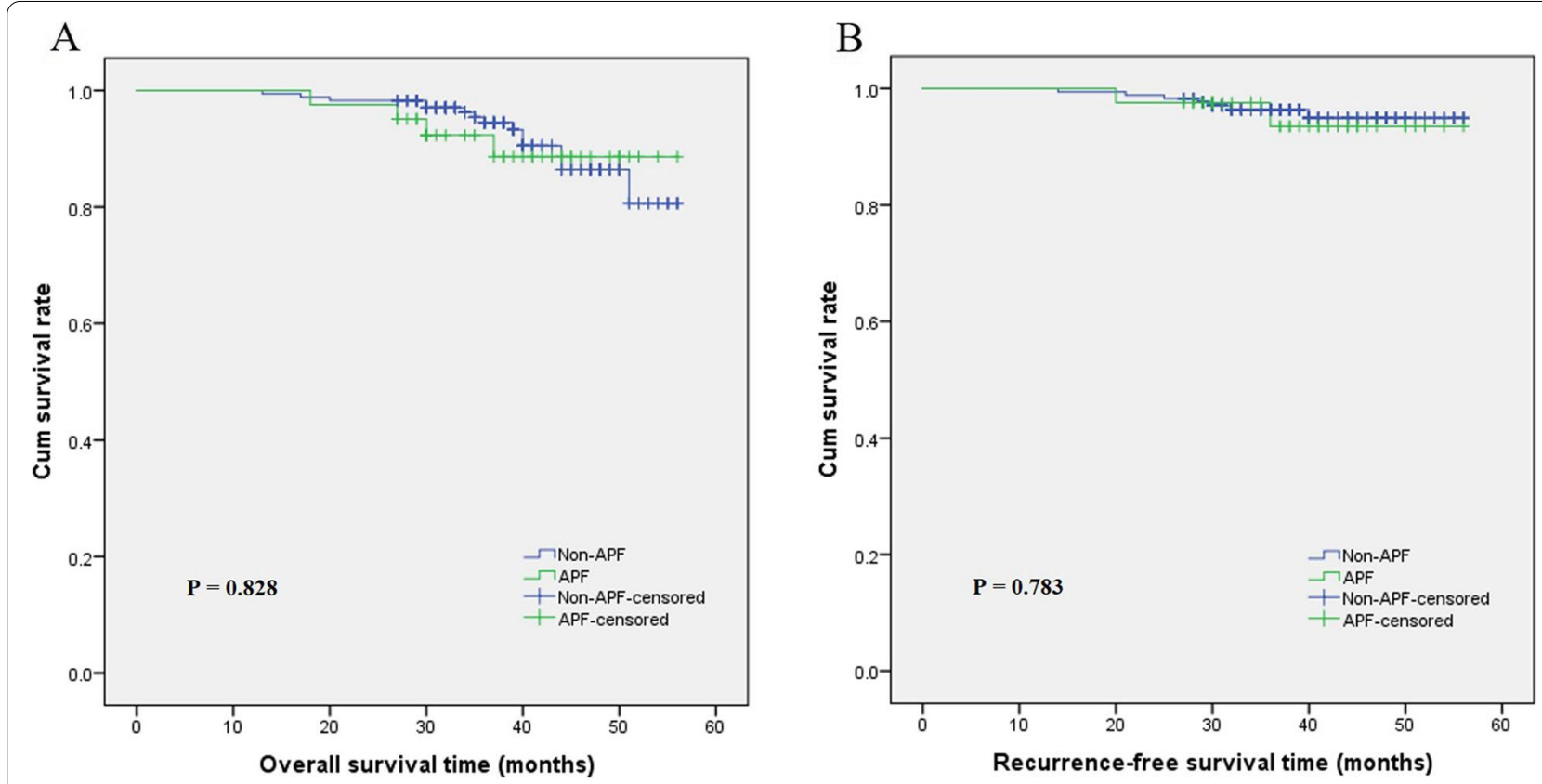

Fig. 3 Kaplan-Meier method was applied to analyze the overall survival (OS) and recurrence-free survival (RFS). There was no significant difference between the APF group and non-APF group in OS $(P=0.828)$ and RFS $(P=0.783)$, respectively

syndrome [27]. This variation manifests in gender as well, as women have more subcutaneous fat than men, while men have more perirenal fat than women [15]. As a result, most studies, including ours, indicate that males have a higher incidence of APF $(P=0.001)$. Furthermore, other clinical factors predicting the presence of APF, such as age, cardiovascular disease, and diabetes mellitus, have been reported in a few studies [12-14, 24]. Notably, in the present study, we found that APF correlated with a decreased preoperative level of eGFR $(P=0.004)$, which 
may suggest that a chronic inflammatory response participates in the formation of APF [28].

To further investigate the predictors of APF, the radiographic parameters were analyzed at the same time. Posterior perinephric fat thickness, as a measurement of intra-abdominal fat, has a significant relationship with APF and complications of MIPN [11, 14]. Perinephric fat stranding was initially observed in cross-sectional imaging under inflammatory conditions, such as pyelonephritis and ureteral obstruction [16], and has also been identified in cases of APF recently. Based on these two radiographic factors, a semiquantitative scoring system called the MAP score has been proposed to predict APF during RAPN [14]. Our multivariate analysis revealed that the MAP score was an independent predictor of APF $(P<0.001)$, providing concomitant external validation in a large cohort of LPN.

As mentioned above, the pathogenesis of APF may correlate with inflammation, while cancer-related inflammation is known to be involved in tumor development and progression, including RCC [29]. Kocher et al. showed that APF was associated with malignant renal histology (versus benign disease) [12], and Thiel et al. revealed that high MAP scores were related to decreased progressionfree survival of RCC [30]. Interestingly, our study failed to elucidate the association between APF and tumoraggressive behaviors, and the oncological outcomes.

There are several limitations in this study. First, considering the difference of treatment strategy between benign and malignant renal tumors, we excluded benign tumors in the study. Second, the limited number of single-center patients and the relatively strong correlations among previously mentioned clinical factors made the application of multivariate model analysis challenging. Third, our definition of APF may require further validation with multicenter and larger cohort studies.

\section{Conclusions}

APF can be preoperatively predicted with the comprehensive assessment of several specific clinical and radiographic factors, including male gender, higher BMI, and the MAP score. The presence of APF is associated with an increased operative time, warm ischemia time, and greater estimated blood loss but has no impact on other perioperative outcomes in LPN. Consequently, the accurate evaluation and adequate understanding of APF will be helpful to counsel patient selection and improve outcomes.

\section{Abbreviations}

APF: Adherent perinephric fat; LPN: Laparoscopic partial nephrectomy; RCC : Renal cell carcinoma; MAP: Mayo Adhesive Probability; CT: Computed tomography; BMI: Body mass index; eGFR: Estimated glomerular filtration rate; WIT: Warm ischemia time; EBL: Estimated blood loss.

\section{Supplementary Information}

The online version contains supplementary material available at https://doi. org/10.1186/s12957-021-02429-6.

Additional file 1 : Table S1. Characteristics of current literatures on the study of adherent perinephric fat in partial nephrectomy

Additional file $\mathbf{2}$ : Table S2. Impact of adherent perinephric fat on perioperative outcomes in laparoscopic partial nephrectomy after homogeneous adjustment for BMI

\section{Acknowledgements}

The authors gratefully thank all of the participants in this study for supporting this study.

\section{Authors' contributions}

LF and DXY designed the study. HL, RL, TTZ, TZ, LKB, DDX and YW collected and analyzed data. LF and HL wrote the paper. DXY revised the paper. The authors read and approved the final manuscript.

\section{Funding}

This study was supported by the Scientific Research Foundation of Anhui Medical University (No. 2019xkj037).

\section{Availability of data and materials}

The datasets generated and analyzed during the current study are not publicly available because we are conducting further investigations but are available from the corresponding author on reasonable request.

\section{Declarations}

Ethics approval and consent to participate

This study was approved by the Ethics Committee of The Second Hospital of Anhui Medical University (No. YX2020-015-F2). The study protocol is performed in accordance with the Declaration of Helsinki. The written informed consent was not required for this retrospective study. The Ethics Committee of The Second Hospital of Anhui Medical University permitted waiving the need of informed consent, and we guaranteed that data used in this study was de-identified.

\section{Consent for publication}

The patients included in the article provided consent for their data to be used in this publication.

\section{Competing interests}

The authors have no conflicts of interest to disclose.

\section{Author details}

${ }^{1}$ Department of Urology, The Second Hospital of Anhui Medical University, 678 FuRong Road, Hefei 230601, Anhui Province, China. ${ }^{2}$ Department of Radiology, The Second Hospital of Anhui Medical University, 678 FuRong Road, Hefei 230601, Anhui Province, China.

Received: 6 May 2021 Accepted: 23 October 2021

Published online: 04 November 2021

References

1. Ljungberg B, Bensalah K, Canfield S, Dabestani S, Hofmann F, Hora M, et al. EAU 9 carcinoma: 2014 update. Eur Urol. 2015:67:913-24.

2. Bravi CA, Larcher A, Capitanio U, Mari A, Antonelli A, Artibani W, et al. Perioperative outcomes of open, laparoscopic, and robotic partial nephrectomy: a prospective multicenter observational study (The 
RECORd 2 Project). Eur Urol Focus. 2021;7(2):390-6. https://doi.org/10. 1016/j.euf.2019.10.013. Epub 2019 Nov 12.

3. Chang KD, Abdel Raheem A, Kim KH, Oh CK, Park SY, Kim YS, et al. Functional and oncological outcomes of open, laparoscopic and robotassisted partial nephrectomy: a multicentre comparative matched-pair analyses with a median of 5 years' follow-up. BJU Int. 2018;122:618-26.

4. Pereira J, Renzulli J 2nd, Pareek G, Moreira D, Guo R, Zhang Z, et al. Perioperative morbidity of open versus minimally invasive partial nephrectomy: a contemporary analysis of the National Surgical Quality Improvement Program. J Endourol. 2018;32:116-23.

5. Guo Y, Xu Q, Chen B, Liu L, Wang Y, Zhu A, et al. Clinical outcomes and effect on intraoperative blood loss and postoperative pain of patients undergoing retroperitoneal laparoscopic partial nephrectomy for complex renal tumors. World J Surg Oncol. 2021;19:282.

6. Tran MGB, Aben KKH, Werkhoven E, Neves JB, Fowler S, Sullivan M, et al. Guideline adherence for the surgical treatment of T1 renal tumours correlates with hospital volume: an analysis from the British Association of Urological Surgeons Nephrectomy Audit. BJU Int. 2020;125:73-81.

7. Nishimura K, Sawada Y, Sugihara N, Funaki K, Koyama K, Noda T, et al. A Iow RENAL Nephrometry Score can avoid the need for the intraoperative insertion of a ureteral catheter in robot-assisted partial nephrectomy. World J Surg Oncol. 2021;19:40.

8. Ficarra V, Novara G, Secco S, Macchi V, Porzionato A, De Caro R, et al. Preoperative aspects and dimensions used for an anatomical (PADUA) classification of renal tumours in patients who are candidates for nephron-sparing surgery. Eur Urol. 2009;56:786-93.

9. Simmons MN, Ching CB, Samplaski MK, Park CH, Gill IS. Kidney tumor location measurement using the $\mathrm{C}$ index method. J Urol. 2010;183:1708-13.

10. Kutikov A, Uzzo RG. The R.E.N.A.L. nephrometry score: a comprehensive standardized system for quantitating renal tumor size, location and depth. J Urol. 2009;182:844-53.

11. Gorin MA, Mullins JK, Pierorazio PM, Jayram G, Allaf ME. Increased intraabdominal fat predicts perioperative complications following minimally invasive partial nephrectomy. Urology. 2013;81:1225-30.

12. Kocher NJ, Kunchala S, Reynolds C, Lehman E, Nie S, Raman JD. Adherent perinephric fat at minimally invasive partial nephrectomy is associated with adverse peri-operative outcomes and malignant renal histology. BJU Int. 2016;117:636-41.

13. Khene ZE, Peyronnet B, Mathieu R, Fardoun T, Verhoest G, Bensalah K. Analysis of the impact of adherent perirenal fat on peri-operative outcomes of robotic partial nephrectomy. World J Urol. 2015:33:1801-6.

14. Davidiuk AJ, Parker AS, Thomas CS, Leibovich BC, Castle EP, Heckman MG, et al. Mayo adhesive probability score: an accurate image-based scoring system to predict adherent perinephric fat in partial nephrectomy. Eur Urol. 2014;66:1165-71.

15. Eisner BH, Zargooshi J, Berger AD, Cooperberg MR, Doyle SM, Sheth S, et al. Gender differences in subcutaneous and perirenal fat distribution. Surg Radiol Anat. 2010;32:879-82.

16. Kim S, Choi SK, Lee SM, Choi T, Lee DG, Min GE, et al. Predictive value of preoperative unenhanced computed tomography during ureteroscopic lithotripsy: a single institute's experience. Korean J Urol. 2013;54:772-7.
17. Gill IS, Desai MM, Kaouk JH, Meraney AM, Murphy DP, Sung GT, et al. Laparoscopic partial nephrectomy for renal tumor: duplicating open surgical techniques. J Urol. 2002;167:469-7 discussion 475-466.

18. Clavien PA, Barkun J, de Oliveira ML, Vauthey JN, Dindo D, Schulick RD, et al. The Clavien-Dindo classification of surgical complications: five-year experience. Ann Surg. 2009;250:187-96.

19. Winfield HN, Donovan JF, Godet AS, Clayman RV. Laparoscopic partial nephrectomy: initial case report for benign disease. J Endourol. 1993:7:521-6.

20. Aboumarzouk OM, Stein RJ, Eyraud R, Haber GP, Chlosta PL, Somani BK, et al. Robotic versus laparoscopic partial nephrectomy: a systematic review and meta-analysis. Eur Urol. 2012;62:1023-33.

21. Wang J, Lu Y, Wu G, Wang T, Wang Y, Zhao H, et al. The role of threedimensional reconstruction in laparoscopic partial nephrectomy for complex renal tumors. World J Surg Oncol. 2019;17:159.

22. Xu J, Xu S, Yao B, Xu R, Xu Y, Sun F, et al. Segmental artery clamping versus main renal artery clamping in nephron-sparing surgery: updated metaanalysis. World J Surg Oncol. 2020;18:210.

23. Zhang F, Gao S, Chen XN, Wu B. Clampless and sutureless laparoscopic partial nephrectomy using monopolar coagulation with or without N-butyl-2-cyanoacrylate. World J Surg Oncol. 2019;17:72.

24. Borregales LD, Adibi M, Thomas AZ, Reis RB, Chery LJ, Devine $C E$, et al. Predicting adherent perinephric fat using preoperative clinical and radiological factors in patients undergoing partial nephrectomy. Eur Urol Focus. 2021;7(2):397-403. https://doi.org/10.1016/j.euf.2019.10.007. Epub 2019 Nov 2.

25. Bylund JR, Qiong H, Crispen PL, Venkatesh R, Strup SE. Association of clinical and radiographic features with perinephric "sticky" fat. J Endourol. 2013:27:370-3.

26. Crewe C, An YA, Scherer PE. The ominous triad of adipose tissue dysfunction: inflammation, fibrosis, and impaired angiogenesis. J Clin Invest. 2017:127:74-82.

27. Després JP, Lemieux I. Abdominal obesity and metabolic syndrome. Nature. 2006;444:881-7.

28. Gupta J, Mitra N, Kanetsky PA, Devaney J, Wing MR, Reilly M, et al. Association between albuminuria, kidney function, and inflammatory biomarker profile in CKD in CRIC. Clin J Am Soc Nephrol. 2012;7:1938-46.

29. Chang Y, An H, Xu L, Zhu Y, Yang Y, Lin Z, et al. Systemic inflammation score predicts postoperative prognosis of patients with clear-cell renal cell carcinoma. Br J Cancer. 2015;113:626-33.

30. Thiel DD, Davidiuk AJ, Meschia C, Serie D, Custer K, Petrou SP, et al. Mayo Adhesive Probability score is associated with localized renal cell carcinoma progression-free survival. Urology. 2016;89:54-60.

\section{Publisher's Note}

Springer Nature remains neutral with regard to jurisdictional claims in published maps and institutional affiliations.

Ready to submit your research? Choose BMC and benefit from

- fast, convenient online submission

- thorough peer review by experienced researchers in your field

- rapid publication on acceptance

- support for research data, including large and complex data types

- gold Open Access which fosters wider collaboration and increased citations

- maximum visibility for your research: over 100M website views per year

At BMC, research is always in progress.

Learn more biomedcentral.com/submissions 